\title{
Convenções e invenções em torno da tópica 5 - \#5 - 6 no processo musical nacionalista no Brasil
}

\author{
George Manoel Farias (Rede Pública Estadual de Ensino de S.C., São José, SC) \\ geofas28@hotmail.com
}

\begin{abstract}
Resumo: Este artigo tem por objetivo averiguar o processo de consolidação da tópica 5 - \#5 - 6 na música brasileira, bem como seu uso como elemento de significação nacionalista em canções de compositores como Pixinguinha, Ary Barroso e Gonzaguinha, buscando estabelecer um diálogo com a teoria semiótica de Roy Wagner, que trata do continuo processo de transformação ao qual os elementos simbólicos de qualquer grupo cultural estão sujeitos.
\end{abstract}

Palavras-chave: Roy Wagner; Teoria das Tópicas; Nacionalismo na Música Popular; Ary Barroso; Pixinguinha; Gonzaguinha.

\section{Conventions and Inventions around of the topic 5-\#5-6 in the nationalist musical process in Brazil}

\begin{abstract}
This article aims at investigating the consolidation of topic 5 - \#5- 6 in Brazilian Music, as well as its use as a national element in songs of compositors as Pixinguinha, Ary Barroso and Gonzaguinha, seeking to establish a dialogue with the semiotic theory of Roy Wagner, that investigates the continuous process of transformation which the simbolic elements of any cutural group are subject.
\end{abstract}

Keywords: Roy Wagner; Theory of topics; Nationalism in Brazilian Popular Music; Ary Barroso; Pixinguinha; Gonzaguinha

\section{1- Introdução}

São muitos os autores que trabalham a questão do nacionalismo como um fenômeno social surgido a partir de processos humanos de "invenção", no sentido de "construção" ou "imaginação" (ANDERSON, 2005; GELLNER, 1981; HOBSBAWM, 1990; GUIBERNAU, 1997). Em meio a tais processos, pode ser destacado o papel exercido pela música no que TURINO $(2003$, p.175) denomina "Nacionalismo Cultural", através do qual os variados recursos de linguagens artísticas atuam de modo a contribuir com a criação e modelagem de variados símbolos que trabalham de forma semiótica para o fortalecimento do sentimento nacional.

Na música brasileira, o uso do termo nacionalismo surge pelas obras de alguns compositores da música de concerto atuantes no cenário musical do final do século XIX e início do século XX, como Brasílio Itiberê da Cunha, Carlos Gomes e Alberto Nepomuceno. Após esses primeiros esforços, são notáveis dois movimentos estéticos de caráter nacionalista durante a primeira metade do século XX. 0 primeiro deles foi a corrente musical do Modernismo Nacionalista, caracterizada nas obras de vários compositores atuantes na música de concerto, tais como Francisco Mignone, Lorenzo Fernandes e Camargo Guarnieri, que buscavam representar musicalmente a identidade nacional brasileira. Algumas ideias do folclorista Mário de Andrade orientavam esses e outros compositores da mesma corrente, e previam um processo no qual a pesquisa de material musical folclórico de várias regiões do país funcionasse como um ponto de partida para que os compositores estabelecessem um processo de estudo e vivência em torno desse material, a ponto de capacitar sua inspiração para a elaboração de obras com características nacionais (TRAVASSOS, 2000; REILY, 1994). 0 segundo movimento ocorreu com o surgimento de uma das ramificações do gênero do samba, denominada "samba-exaltação", dentro da qual exerceu pioneiro papel o compositor Ary Barroso, através de sua composição Aquarela do Brasil, peça que após seu sucesso e grande repercussão passou a funcionar como uma referência de "brasilidade musical" no âmbito da música popular.

Além do ingrediente do samba (FARIAS, 2010, p.68-91), recentemente promovido a gênero musical representante da musicalidade nacional, tanto no Brasil como no exterior (VIANNA, 2004), a peça Aquarela do Brasil trazia uma série de outros elementos marcantes, desde o plano poético (de sua letra) até os planos melódico, rítmico e harmônico (de sua música) presentes nela. Um 
destes elementos diz respeito a uma transição intervalar harmônica entre quinta justa, quinta aumentada e sexta maior (5 - \#5 - 6) presente no acompanhamento da peça em uma de suas seções estruturais. Esse fragmento pode ser concebido como uma espécie de tópica da música brasileira (PIEDADE, 2006) haja vista tratar-se de um elemento recorrente na produção musical popular nacional, adquirindo em cada caso uma forte associação semiótica com a ideia musical de Brasil. ${ }^{1}$

Pretendo neste artigo desenvolver um pequeno estudo em torno do estabelecimento da transição 5 - \#5 - 6 como uma tópica da música brasileira em algumas peças musicais em que ela está presente, buscando estabelecer uma relação com o fenômeno semiótico descrito por Roy Wagner em "A Invenção da Cultura" e ao longo de sua obra escrita, sendo caracterizado por uma dialética que atua nos processos de simbolização em variadas culturas. Um dos elementos que caracteriza essa dialética diz respeito à simbolização convencional e os processos de constante "diferenciação" em torno dessas convenções através dos quais os símbolos passam por constantes transformações dentro de uma cultura (WAGNER, 2010, p.84-85).

Antes de seguir, é bom lembrar que Roy Wagner traz uma concepção não tão negativa do termo "invenção" (GOLDMAN, 2011, p.198), que faz de certa forma uma certa contraposição com alguns teóricos da questão do fenômeno do nacionalismo aqui já citados no primeiro parágrafo. Ao invés de pensar "invenção" como algo próximo do plano imaginativo ou mais fictício, o encara como um processo natural e contínuo em qualquer sociedade possuidora de suas tradições culturais, estas sendo constantemente "criadas" ou "descobertas" pelos atores que nela interagem e produzem ou descobrem signos.

Na posição de um desses atores, vou tentar nas próximas páginas desenvolver 0 estudo proposto sobre um dos elementos simbólicos que ajudaram a "inventar" uma tradição musical nacional e, de certa forma e na concepção de Wagner, procurar exercer um pouco dessa ação "inventiva".

\section{2 - A tópica 5 - \#5 - 6 na música brasileira.}

É difícil precisar o momento em que a tópica 5 - \#5 - 6 foi usada pela primeira vez na música brasileira com algum tipo de significado nacionalista. Não pode ser descartada a possibilidade de tratar-se de um elemento presente em alguma antiga cantiga folclórica ou em alguma prática musical de algum grupo cultural nativo, dentro da grande diversidade de manifestações existentes no Brasil. No ano de 2008, quando tentei levantar tal questão em um trabalho acadêmico que investigava as possiveis fontes de inspiração de Ary Barroso para usar esta tópica em Aquarela do Brasil, fui alertado por um de meus professores que a mesma estaria presente na peça Carinhoso, de Pixinguinha. Um pouco mais tarde, o mesmo professor sugeriu-me realizar uma atenta audição da ópera 0 Guarani (// Guarany) do compositor Antonio Carlos Gomes (1836-1896), afirmando ter percebido nessa peça a presença do mesmo elemento sonoro. ${ }^{2} \mathrm{Na}$ época, acabei não me aprofundando nessa questão, deixando tais ideias "adormecidas". Mas, no momento da realização deste presente estudo, optei por resgatar aquela orientação. Assim, constatei através da audição da mesma peça duas breves exposições da transição 5 - \#5 - 6 nos trechos destacados abaixo no Ex. 1 (c.150-152 e c.154-155):

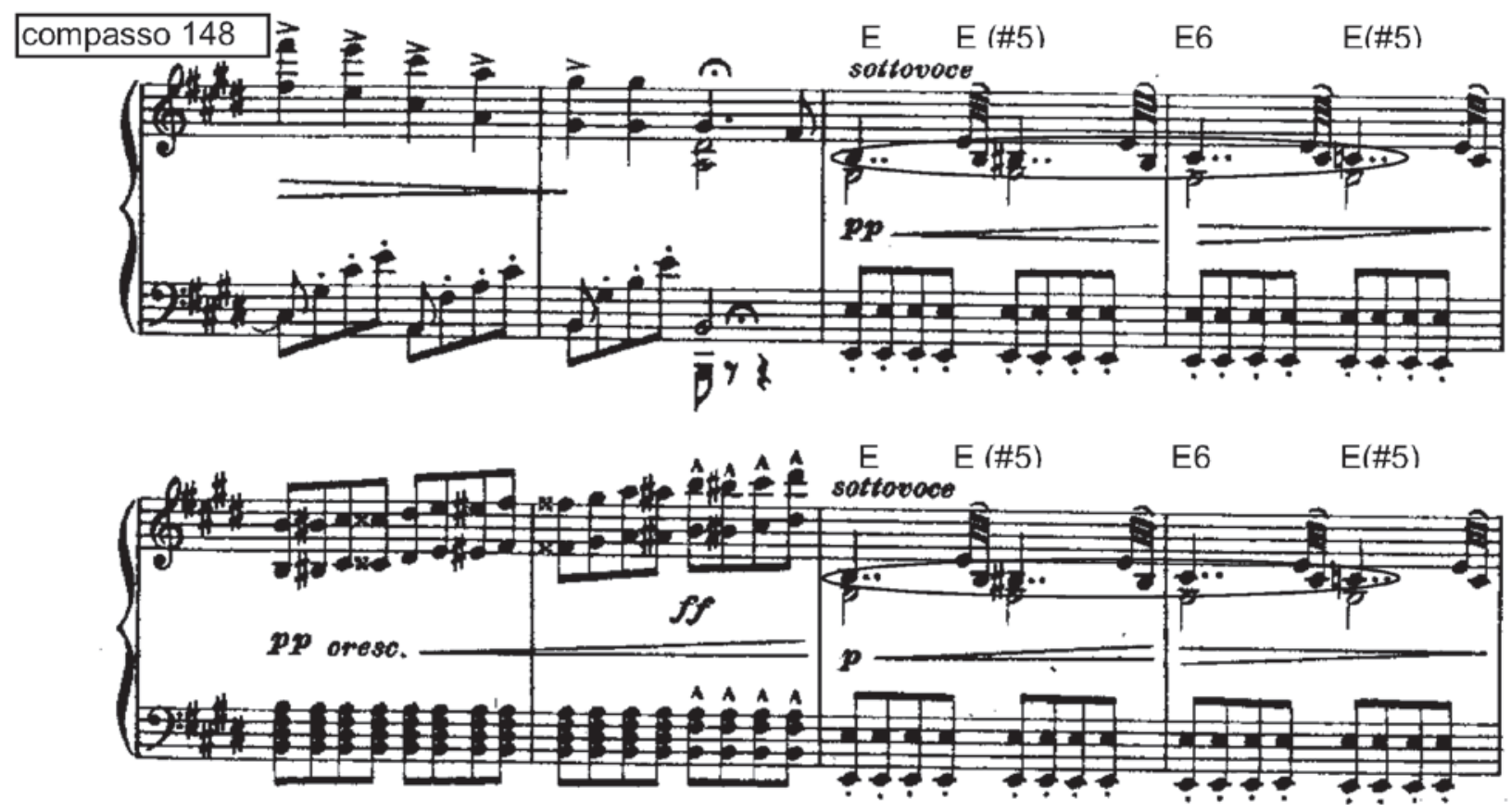

Ex. 1 - Trecho de Redução para Piano da Sinfonia da Ópera 0 Guarani, de Carlos Gomes (c.148-155). Circulados, em destaque, a exposição da transição 5 - \#5 - 6 (notas Si, Si Sustenido e Dó Sustenido). 
A primeira impressão que tive ao ouvir a gravação de uma execução orquestral do mesmo trecho da peça foi de tratar-se de algo sonoramente familiar com o pouco que conheço de música considerada italiana. É interessante observar que Carlos Gomes foi considerado por muitos historiadores da música como o primeiro compositor nacionalista brasileiro, tendo tido grande destaque na segunda metade do século XIX. É bom lembrar que Carlos Gomes, apesar de receber em sua época tal rótulo, teve como característica sonora marcante de suas óperas a presença de um certo italianismo, sendo os aspectos nacionais de sua obra evidenciados mais pelas temáticas contextuais exploradas em suas peças do que pelos aspectos do plano sonoro. ${ }^{3}$ Isso foi apontado posteriormente ao falecimento de Carlos Gomes, na década de 1920, pelas críticas exercidas ao compositor por personalidades do modernismo, denunciando a ausência em sua obra de elementos musicais típicos do folclore nacional (TRAVASSOS, 2000, p.22).

Já na peça musical Carinhoso, a mesma transição 5 - \#5 6 é destacada em seu acompanhamento de maneira bem mais enfática do que na ópera 0 Guarani, como pode ser visualizado no Ex.2. Não seria fácil saber com precisão se Alfredo da Rocha Vianna (1897-1973), o Pixinguinha, quando compôs Carinhoso, teria sido inspirado ou não por esse tão curto fragmento da ópera de Carlos Gomes, da mesma forma que é incerto que o mesmo fragmento tenha tido, antes da composição de Pixinguinha, um uso convencional no âmbito da musicalidade brasileira.

Porém, a partir do momento em que o 5 - \#5 - 6 foi usado na composição de Pixinguinha, é possível dizer que ele adquiriu um outro tipo de conotação simbólica. Para compreender um pouco do contexto em torno da peça Carinhoso, é importante mencionar que se trata de um choro composto em 1917, o qual Pixinguinha optou por deixar de executar por um longo período, deixando-o guardado. 0 motivo seria sua estrutura de duas partes, atípica ao gênero do choro, convencionado, até então, na forma Rondó. Vencida essa barreira da tradição do gênero, ${ }^{4}$ Carinhoso foi gravado em 1928 pela Orquestra Típica Pixinguinha-Donga, de forma instrumental e regravado no ano seguinte pela Orquestra Victor Brasileira. ${ }^{5}$
Mesmo sem ter sido uma peça musical declaradamente nacionalista, assim como o gênero do choro em geral, Carinhoso foi uma obra de destaque no contexto da musicalidade brasileira que, com sua gravação definitiva com a letra em 1937, antecedeu de forma direta o "sambaexaltação", categoria do samba pela qual a música popular pela primeira vez consolidou um movimento de representação musical direta de uma identidade nacional. Outro ponto a considerar é que o choro, desde seu surgimento, estabeleceu-se como uma música de características fortemente ligadas a uma tradição musical de Brasil, integrando um conjunto de "gêneros musicais nacionalmente estabelecidos" (FARIAS, 2010, p.91).

No processo de estabelecimento da tópica 5 - \#5 - 6 na música brasileira, adquirindo essa conotação nacionalista, pode ser averiguada uma contínua relação entre convenção e diferenciação, "os dois mecanismos semióticos básicos da semiótica particular adotada por Wagner" (GOLDMAN, 2011, p.207). WAGNER (2010, p.76-77) destaca que para o estabelecimento das convenções simbólicas de uma cultura são necessárias associações entre símbolos e os contextos nos quais estes são usados. Tal ideia pode ser relacionada com o próprio conceito musical de tópica, já que ela só é estabelecida a partir do momento em que há uma ligação entre um determinado elemento retórico da linguagem musical e um determinado contexto cultural. Como destaca PIEDADE (2006, p.12):

\footnotetext{
"Tópicas seriam, portanto, as figuras da retórica musical. A ideia de figura e de retórica musical pressupõe, portanto, uma compreensão da música enquanto discurso. As unidades musicais deste discurso são, muitas vezes, atribuidas de qualidade ou ethós, isto por meio de convenção cultural (diga-se, histórica e tácita)".
}

0 que quero dizer é que a partir do momento em que 0 5 - \#5 - 6 passou a ser usado por variados compositores em um contexto semelhante, associado a discursos musicais, poéticos e temáticos de nacionalidade, este deixa de ser apenas uma mera sequência de notas, uma "coisa em si mesma" e passa a adquirir um outro tipo de significado, relacionado ao contexto no qual ele é compartilhado (WAGNER, 2010, p.77). A conversão do 5 - \#5 - 6 em tópica da música brasileira consolidase provavelmente a partir de seu uso por Ary Barroso

$\mathrm{IIIm}$

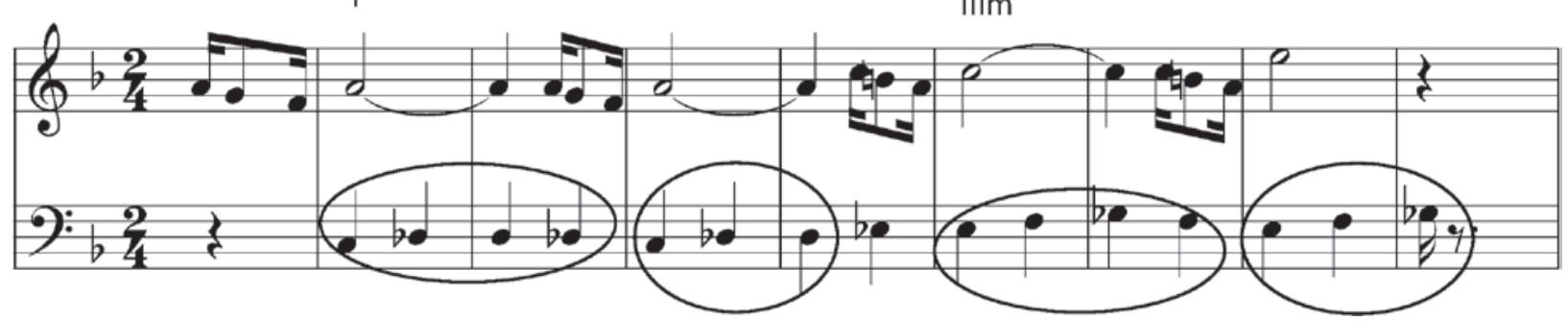

Ex. 2 - Trecho inicial da peça Carinhoso de Pixinguinha, transcrito da versão gravada em 1929 pela Orquestra Victor Brasileira. Circulados, em destaque, a exposição das transições 5 - \#5 - 6 aplicadas sobre o I grau maior (Fá Maior) e III grau menor (Lá Menor). (Transcrição Própria) 
(1903-1964) em Aquarela do Brasil. Até então, por sua breve presença em 0 Guarani e mais marcante em Carinhoso, a transição 5 - \#5 - 6 poderia ser concebida como um elemento simbólico disponível para ser usado, uma convenção ao alcance de outros compositores que poderiam, a partir daquele momento, exercer uma atitude diferenciadora sobre ela: é o que fez Ary Barroso.

Se "simbolizar é sempre utilizar de forma 'diferenciada' símbolos que fazem parte de uma 'convenção'" (GOLDMAN, 2010, p.207), Ary Barroso reutiliza de forma especial o mesmo elemento. Em um processo que pode ser comparado a uma metaforização, Ary Barroso, além de "sambalizar" o 5 - \#5 - 6, o conjuga com um padrão rítmico bastante similar ao executado por um tamborim na batucada de samba (FARIAS, 2010, p.120-121), tal como está destacado abaixo no Ex.3:

Associado a toda carga simbólica musical e poética contida na peça Aquarela do Brasil, o processo de iconização de um típico instrumento musical da percussão afro-brasileira faz com que a tópica 5 - \#5 - 6 funcione nesse momento "como se" fosse um tamborim: "Quando um símbolo é usado de modo não convencional, como na formação de uma metáfora ou de um tropo de uma nova ordem, um novo elemento é introduzido simultaneamente à nova simbolização" (WAGNER, 2010, p.85). Esse novo elemento, a iconização do tamborim, ajudava naquele momento a fortalecer o 5 - \#5 - 6 como um forte símbolo da identidade nacional, consolidandose como uma tópica na musicalidade brasileira. Outro elemento diferenciante introduzido no uso desta figura de linguagem musical em Aquarela do Brasil está no fato de seu sentido melódico ser exclusivamente ascendente (grave - agudo), sem o retorno para o grave existente anteriormente na peça Carinhoso. 0 efeito sensorial dessa modificação é o de produzir no ouvinte certo otimismo, que pode ser relacionado com aquele momento de Brasil que também caracterizava o samba-exaltação, marcado por um clima patriótico otimista e ufanista.

A partir de Aquarela do Brasil, sempre que Ary Barroso e outros compositores voltaram a usar o 5 - \#5 - 6, podese dizer que faziam uso de uma espécie de convenção sonora bastante apropriada para referir-se à ideia de Brasil. Podem ser citadas peças do próprio compositor Ary Barroso, em que a mesma tópica esteve presente: Brasil Moreno, gravada em 1941 e Isto Aqui o que é, de 1942, ambas imersas na categoria "samba-exaltação", são exemplos dessa re-utilização do 5 - \#5 - 6 como convenção simbólica de brasilidade musical. Jacob do Bandolim, na marcante introdução do samba-choro instrumental Bole-bole, gravado em 1951 pelo próprio compositor, apresenta a mesma tópica 5 - \#5 - 6 de maneira bastante enfática e enérgica, mas com a mesma divisão rítmica usada em Carinhoso e, da mesma maneira, com sentido melódico ascendente e descente.

Porém, segundo a teoria semiótica defendida por Roy Wagner, o processo de criação de novos elementos em torno de uma convenção estabelecida é sempre contínuo no ambiente de uma cultura. Até a década de 1980 a sociedade brasileira passou por muitas transformações que se refletiam na expressão artístico-musical. Pode-se dizer que a noção de identidade musical, em termos de gêneros musicais para tratar de assuntos poéticos relacionados à nação brasileira não estava mais limitada ao samba, embora o mesmo ainda continuasse predominante, como talvez até hoje esteja. A ascensão de outros gêneros musicais associados a outras regiões do país além do Rio de Janeiro, ${ }_{1}^{6}$ como a música caipira e a música nordestina, ajudavam a enriquecer com outras vozes a noção musical de Brasil. No campo político-
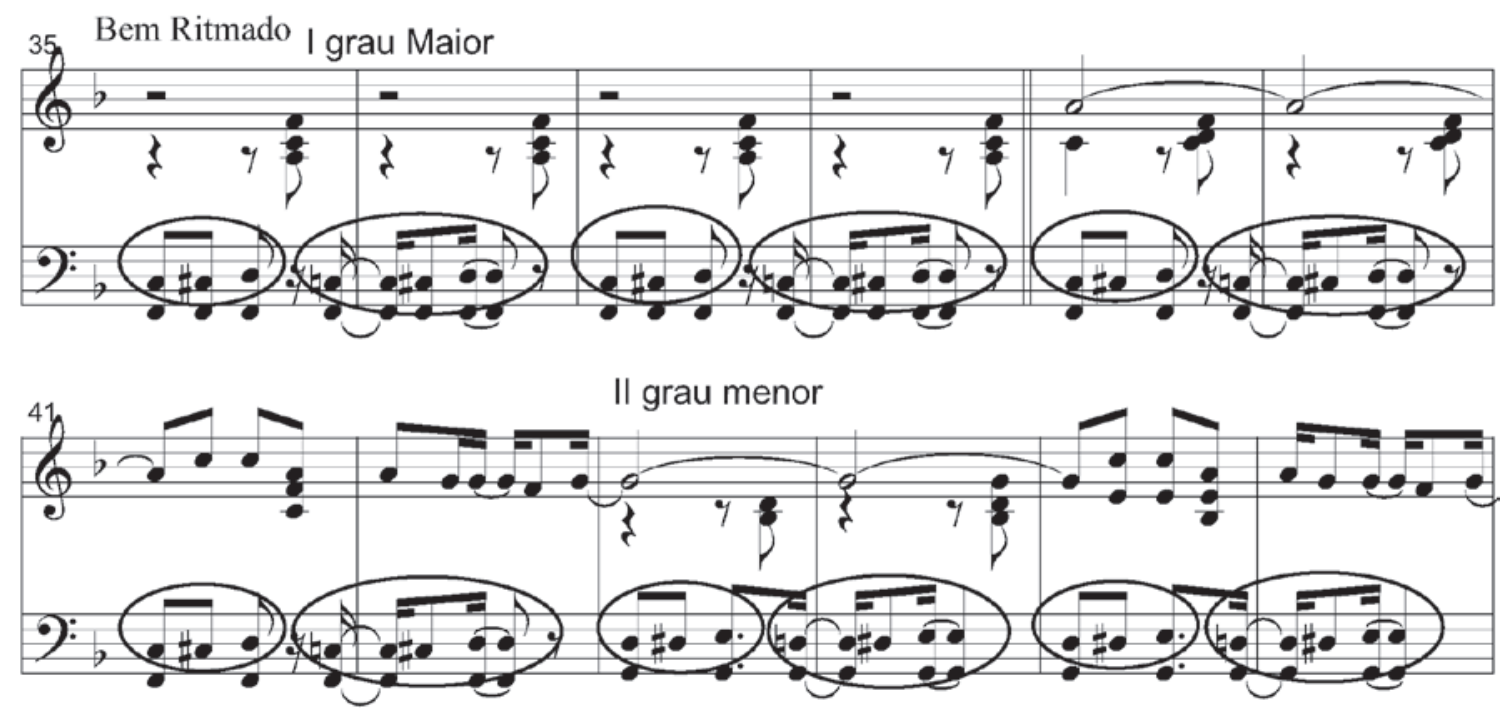

Ex. 3 - Trecho de redução para Piano de Aquarela do Brasil, de Ary Barroso, transcrito de MASCARENHAS (1982, p.2-3). Circulados, em destaque, a exposição das transições 5 - \#5- 6 aplicadas sobre o I grau maior (Fá Maior) e II grau menor (Sol Menor). 
social, o período que sucedeu a ditadura militar no Brasil é marcado por grandes problemas econômicos, desigualdades sociais e desilusões com relação à classe política, sentimentos que transpareciam nas manifestações de compositores como Cazuza e Renato Russo, em peças musicais como Brasil e Que País é este, respectivamente, caracterizando uma mudança paradigmática na maneira pela qual os artistas da música brasileira passavam a se referir poeticamente à nação. ${ }^{7}$

Luiz Gonzaga Júnior (1945-1991), o Gonzaguinha, seguiu esse novo paradigma ao trabalhar poeticamente de maneira crítica muitas das questões relacionadas com aquele momento da nação brasileira através de sua composição intitulada É. No plano sonoro, a tópica 5 \#5 - 6 era novamente utilizada em uma canção popular que fazia referência poética à "gente brasileira", sendo exposta na introdução violonística, porém, modificada pela ação "diferenciante" do artista que a re-utiliza, já que "as associações simbólicas que as pessoas compartilham [...] são tão dependentes da contínua reinvenção quanto as idiossincrasias, detalhes e cacoetes que elas percebem em si mesmas ou no mundo que as cerca" (WAGNER, 2010, p.94). Gonzaguinha não se limitou em usar a mesma tópica como uma simples citação. Pelo contrário, atuou nela e a expôs no trecho introdutório com uma interessante variação rítmica: embora Étenha em seu acompanhamento a predominância do ritmo do samba, os seus primeiros compassos trazem a rítmica de um baião, o mesmo gênero musical consagrado por seu pai, Luiz Gonzaga, a partir do final da década de 1940. Tal gênero musical consistiu também em um veículo pelo qual a triste realidade de um Brasil marcado pela pobreza e pela seca, situação marcante na região nordeste, era exposta ao restante do país em canções como Asa Branca e Vozes da Seca.

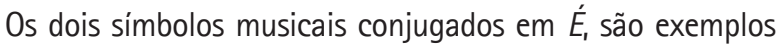
de símbolos que haviam assimilado os contextos nos quais eram convencionalmente usados, dentro do que Wagner chama de "obviação" (WAGNER, 1978, p.31). A tópica, aqui em questão, já havia assumido um contexto relacionado com a identidade nacional desde seu uso nas peças Carinhoso e Aquarela do Brasil. Já o gênero do baião, que é conjugado ao 5 - \#5 - 6, havia também assumido um contexto relacionado com o nordeste do país, o que incluía toda a dura realidade social da região caracterizada pela seca. ${ }^{8}$

Como é possível verificar no Ex.4, após uma breve introdução instrumental de oito compassos no ritmo do Baião, Gonzaguinha, ao começar a cantar, modifica sutilmente a "batida" de violão substituindo o ritmo do baião pelo do


Ex. 4 - Trecho inicial da peça $E_{1}$ de Gonzaguinha. Em destaque a transição 5 - \#5 - 6 aplicada ao

I Grau Maior (C) e II Grau menor (Dm), bem como a mudança rítmica do acompanhamento (violão) entre os oito compassos introdutórios e a parte vocal. (Transcrição própria) 
samba. Em sua mensagem poética, Gonzaguinha expõe tudo o que "a gente", o povo brasileiro, reivindica: "valer o nosso amor", "valer nosso suor", "valer o nosso humor", "do bom e do melhor", etc. Em Aquarela do Brasil, a tópica 5 \#5 - 6 era usada conjuntamente com o samba para ajudar a expressar apenas as "qualidades" que o país possuía, e o seu sentido melódico exclusivamente ascendente, poderia estar ajudando a ocultar aqueles elementos negativos da nação: como se fosse um "pra frente Brasil". 0 uso que Gonzaguinha faz da tópica, usando os dois sentidos melódicos (ascendente e descendente), não nega o contexto anterior que o símbolo adquiriu na Aquarela do Brasil, mas pode ajudar a reconhecer os "problemas da nação", apontando no texto poético a necessidade de ações políticas para diminuir as injustiças sociais no país.

\section{3 - Considerações Finais}

Os fenômenos semióticos descritos por Roy Wagner em sua obra demonstram um processo pelo qual os símbolos produzidos por uma cultura passam por um fluxo contínuo e simultâneo de ações que estabelecem e alteram constantemente o conteúdo desses mesmos símbolos. A relação de tais fenômenos com a trajetória de estabelecimento do 5 - \#5 - 6 como uma tópica da música brasileira pode ser oportuna e esclarecedora, tanto para uma melhor compreensão do processo de uso deste elemento em repertórios de variados períodos da música brasileira, como para evidenciar a própria noção de tópica como uma "figura de linguagem musical" relacionada com um determinado contexto cultural.

0 estabelecimento inicial da mesma tópica na música brasileira, vindo a tornar-se um recorrente símbolo identitário da nação, parece mascarar uma certa naturalidade no que diz respeito à ligação entre a mesma tópica e a musicalidade brasileira: como a "ilusão necessária" da existência do inato, tal como ocorre na formação da carga simbólica de qualquer comunidade: "nossos símbolos não se relacionam com nenhuma 'realidade' externa; no máximo referem-se a outras simbolizações, que percebemos como realidade" (WAGNER, 2010, p.83).

Mas, o uso da tópica 5 - \#5 - 6 como referência de identidade nacional não permaneceu estático. Adquirindo propriedade convencional, teve na sua re-utilização a constante atuação diferenciadora de compositores como Ary Barroso e Gonzaguinha, que atuando nela por meio de metáforas ou a conjugando com outros símbolos, alteraram, a cada passo, a convenção e os próprios contextos com os quais a tópica estava relacionada.

\section{Referências}

ANDERSON, Benedict. Comunidades Imaginadas: Reflexões Sobre a Origem e a Expansão do Nacionalismo. Lisboa: Edições 70, 2005.

CABRAL, Sérgio. Pixinguinha : vida e obra. 4. ed. Rio de Janeiro: FUNARTE, 2007.

FARIAS, George Manoel. Um tabuleiro bem brasileiro: Ary Barroso e o processo de construção de uma expressão musical nacional. Florianópolis: UDESC, 2010. Disponível [on line] em http://www.pergamumweb.udesc.br/dadosbu/000000/00000000000F/00000FB1.pdf

GELLNER, Ernest. Nacionalismo e Democracia. Brasilia: Ed. da UnB, 1981.

GOLDMAN, Márcio. O Fim da Antropologia. Resenha crítica de "A Invenção da Cultura" de Roy Wagner. In: Novos Estudos Cebrap, n. 89, 2011, p.195-211.

GOMES, Carlos. // Guarany. plate B.A. 7136, São Paulo: Ricordi, n.d.(ca.1920). Disponível [on line] em http://imslp.org/ wiki/II_Guarany_(Gomes,_Carlos)

NASCIMENTO JÚNIOR, Luiz Gonzaga do. É. Álbum: Corações Marginais (faixa 4). WEA: 1988. Disco (LP) de 33 rpm. GUIBERNAU, Montserrat. Nacionalismos: O Estado Nacional e o Nacionalismo no Séc. XX. Rio de Janeiro: Zahar, 1997.

HOBSBAWM, Eric. Nações e Nacionalismo Desde 1780: Programa, Mito e Realidade. Rio de Janeiro: Paz e Terra, 1990.

MASCARENHAS, Mário. O melhor da música popular brasileira : com cifras para piano, órgão, violão e acordeon. São Paulo : Irmãos Vitale, 1982.

PIEDADE, Acácio Tadeu de Camargo. Música Popular, Expressão e Sentido: comentários sobre a Teoria das Tópicas na Música Brasileira. Artigo. Anais do III Encontro Nacional da Associação Brasileira de Etnomusicologia (ABET), 2006. p.11-14. Disponível [on line] em http://www.pesquisamusicaufpb.com.br/Masters/anais_abet2006.pdf. Acessado em 2008.

PIXINGUINHA. Carinhos. Intérprete: Orquestra Victor Brasileira. Álbum n 33209. Victor: 1929. Disco de 78 rpm. Disponível [on line] em http://acervos.ims.uol.com.br/

REILY, Suzel Ana. Macunaíma's Music: National Identity and Ethnomusicological Research in Brazil. In: STOKES, Martin. (ed.) Ethnicity, Identity and Music: the musical construction of place. Oxford/Providence: Berg, 1994. p.71-96. 
SEVERIANO, Jairo; MELLO, Zuza Homem de. A Canção no Tempo: 85 Anos de Músicas Brasileiras. Vol.1: 1901 - 1957. 6ª ed. São Paulo: Ed. 34, 2006.

SOARES, Astréia. Outras conversas sobres os jeitos do Brasil: 0 nacionalismo na Música Popular. São Paulo: Annablume/ FAPESP, 2002.

TRAVASSOS, Elizabeth. Modernismo e Música Brasileira. Rio de Janeiro: Jorge Zahar, 2000.

TURINO, Thomas. Nationalism and Latin American Music: Selected Case Studies and Theoretical Considerations. Artigo. Latin American Music Review, vol. 24,nr. 2, fall/winter 2003, p.169-208.

VIANNA, Hermano. O Mistério do Samba. 5a edição Rio de Janeiro: Jorge Zahar Editor; Editora UFRJ, 2004.

WAGNER, Roy. A invenção da cultura. São Paulo: Cosac Naify, 2010.

WAGNER, Roy. Lethal Speech:Daribi Myth as Symbolic Obviation. Symbol, Myth and Ritual Series. Ithaca: Cornell University Press, 1978.

WAGNER, Roy. Symbols that Stand for Themselves. Chicago and London: The University of Chicago Press, 1986.

\section{Notas}

1 A aplicação da "teoria das tópicas" na música brasileira tem sido objeto de estudo de alguns trabalhos do musicólogo-etnomusicólogo e antropólogo Acácio Tadeu de Camargo Piedade. Tópicas, neste caso, seriam definidas como figuras de retórica musical que integram o "discurso musical" usado por um determinado grupo cultural, possuindo essas também uma relação de significado com aspectos contextuais e sonoros que constituem a musicalidade do mesmo grupo.

2 Referência ao Prof. Dr. Guilherme Antonio Sauerbronn de Barros, docente do PPGMUS da UDESC.

3 Refiro-me às "sonoridades nacionais" dentro de uma concepção modernista de nacionalismo musical, baseada na presença de elementos musicais coletados em manifestações folclóricas e de grupos étnicos pertencentes à cultura nacional.

4 Nesse processo, antecedeu Carinhoso outro choro: Lamentos, gravado um pouco antes, mas que recebeu algumas críticas, justamente devido a sua estrutura de duas partes. Tal característica, entre outras, levava os críticos a afirmarem existir tanto em Lamentos como em Carinhoso características do jazz norte-americano que "ameaçavam" a autenticidade da música brasileira (CABRAL, 2007, p.138-139).

5 A peça recebeu o texto poético pelo qual é tão conhecida até os dias atuais apenas em 1937, por Braguinha, também conhecido como João de Barro.

6 Gênero predominante na expressão musical da identidade nacional durante as décadas de 1930 e 1940.

7 Paradigmas denominados por Soares (2002, p.130) como "Fora da Ordem" e "Nova Ordem", "cujo eixo temático dá relevância à questão da ordem nacional e não ao inventário de valores nacionais homogeneizáveis na sua representação enquanto Aquarelas ou Geleias".

8 Wagner faz uso de um exemplo musical que pode ser relacionado com a assimilação de contextos pelas sonoridades, quando menciona que "a tonalidade de Si menor jamais foi a mesma após a Missa de Bach e a tonalidade de Dó sustenido menor, após o Quarteto de Beethoven" (WAGNER, 1986, p.11, tradução nossa).

George Manoel Farias é Mestre em Música (Musicologia - Etnomusicologia) pela Universidade do Estado de Santa Catarina (2010), quando, sob orientação do Prof. Dr. Acácio Tadeu de Camargo Piedade, desenvolveu a dissertação intitulada Um Tabuleiro Bem Brasileiro: Ary Barroso e o Processo de Construção de uma Expressão Musical Nacional. Atua profissionalmente como professor efetivo de Artes da Rede Pública Estadual de Ensino do Estado de Santa Catarina, desde 2002, lecionando educação musical nos níveis de ensino fundamental e médio. Tem experiência profissional como músico, integrando atualmente, como trompetista, a banda Sociedade Musical União Josefense. Já integrou também, como violonista, a Orquestra de Violões da UDESC (1997-1998) e, como guitarrista, a Big Band da UDESC (2002) e a banda Roadhouse (1997 - 2004). 